\title{
Effects of carbonaceous nanoparticles from low-emission and older diesel engines on human skin cells
}

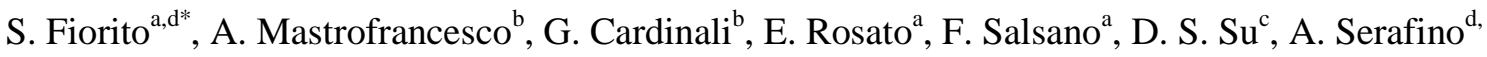 \\ M. Picardo . \\ ${ }^{\mathrm{a}, \mathrm{d}}$ Department of Clinical Medicine, Sapienza University-CNR, Rome, Italy \\ ${ }^{\mathrm{b}}$ Skin Physiopathology Laboratory, San Gallicano Dermatologic Institute, Rome, Italy \\ ${ }^{c}$ Fritz Haber Institute of the Max Planck Society, Berlin, Germany \\ ${ }^{\mathrm{d}}$ Institute of Translational Pharmacology, CNR, Rome, Italy
}

*Corresponding author: e-mail silvana.fiorito@uniroma1.it,

Received 8 March 2011; Accepted 13 July 2011; Available online 23 July 2011

\begin{abstract}
Diesel exhaust particles (DEP) are major constituents of ambient air pollution and are associated with respiratory and cardiovascular diseases as well skin cell alterations in vitro. The epidermal cells are among the first cell populations exposed to chemical pollutants, including DEP, and are an important source of pro-inflammatory mediators. We evaluated the effects of carbonaceous soot particles from current low-emission (Euro IV) diesel engines on the oxidative and inflammatory response of normal human skin cells and compared the results with those induced by carbonaceous soot particles from an older diesel engine (BS) operating under black smoke conditions. We observed that both soot nanoparticles were spontaneously internalised by keratinocytes and distributed mostly around the cell nucleus. Moreover, at the same mass concentration, Euro IV soot particles exhibited a much higher oxidative, pro-fibrotic and toxic potential on these cell types than soot particles from the older diesel engine. These results are in agreement with and confirm our previous findings on human macrophage cells and strengthen the assumption that, at the same mass concentration, soot particles produced under low emission conditions are more cytotoxic than particles from the older diesel engine. This effect could be assigned to the defective surface structure of Euro IV diesel soot, rendering it highly active. Our findings highlight that the reduction of soot emission in terms of mass does not automatically lead to a reduction of the dangerous effects and show that soot particles from different diesel engines possess different biological behaviour towards human cells.
\end{abstract}

\section{Introduction}

Air pollution poses a severe risk for human health in industrialized countries. Both gaseous and particulate emissions resulting from motor vehicle traffic contribute to this phenomenon. Diesel exhaust particles (DEP) are among the most abundant components of particulate matter with an aerodynamic diameter $<2.5 \mu \mathrm{m}$ (PM2.5). DEP are a category of particulate matter (PM) derived from diesel fossil fuels and combustible engines. PM is divided into three major size categories: ultra-fine $(<0.1 \mu \mathrm{m})$, fine $(<2.5 \mu \mathrm{m})$, and coarse $(<10 \mu \mathrm{m}$ and $>2.5 \mu \mathrm{m})$. Ultra-fine particles are more likely to enter circulation and are associated with the major oxidative and pro-inflammatory effects of PM [1]. Particles of nano-sized dimension, as small aggregates of carbonaceous particles less than $100 \mathrm{~nm}$, constitute the most part of DEP [2] and represent the greatest concern to human health because they remain in the atmosphere for long periods, invade the indoor air environment, and can be breathed most deeply into the lungs where they are likely to be more toxic than coarse particles [3]. The exposure of animal and human subjects to DEP for experimental purposes has clearly shown the oxidant and pro-inflammatory nature of DEP [4] as a direct consequence of their ability to induce reactive oxygen species (ROS) and oxidative stress [5]. Epidemiological and experimental studies indicate that DEP are capable of inducing intense inflammatory reactions in airways and may favour allergic sensitization [6-9]. Like airway epithelial cells, the epidermal cells are among the first cell populations that are exposed to chemical pollutants, including DEP, and are an important source of proinflammatory mediators [10-11]. DEP have been shown to induce the production of pro-inflammatory cytokines by human dermal keratinocytes and are suggested to be involved in the initiation or pathogenesis of allergic or nonallergic skin inflammation due to their ability to generate 
reactive oxygen species (ROS) through redox reactions [12]. In fact, DEP-induced toxicity is related to redox cycling chemicals and their capacity to generate oxidative stress. DEP leads to the activation of a genetic antioxidant response element (ARE), resulting in the expression of phase II and antioxidant enzymes. Activation of the ARE is dependent on the transcription factor Nrf-2 that induces the expression of heme oxygenase 1 (HO-1), NAD (P) Hquinone oxidoreductase (NQO1), GST and superoxide dismutase 3 (SOD-3) [13].These enzymes exert cytoprotective, antioxidant and anti-inflammatory effects in lungs. In detail, HO-1 has emerged as an important phase II and antiinflammatory enzyme that is highly up-regulated by oxidative stress [14]. In skin, HO-1 can be induced by a wide variety of stimuli, including hypoxia, UV radiation, heavy metals, Hydrogen-peroxide. This adaptive response of HO1 to cytotoxic stimuli implies that HO-1 may function as a critical cytoprotective molecule [14]. In addition, recent studies have demonstrated important pro-inflammatory roles for two matrix metalloproteinases (MMPs): MMP-3 and MMP-9, secreted by fibroblasts, in acute lung injury [15]. A role for MMP-3 in skin cell inflammation has also been demonstrated [16]. These proteinases can be generated by inflammatory cells, and have the ability to degrade proteoglycans and thus potentially enhance fibrosis and smooth muscle proliferation through their ability to release and activate latent matrix bound growth factors. The increasing penetration of diesel cars in the market forced regulation to introduce more stringent emission standards. All major automobile companies have developed low emission engines as well as filters for soot particles. Research and development strategies have focused on the reduction of soot emission, yet have neglected the question of how changes in soot quality may change its effect on human health. In a previous study we observed that nanoparticulate from a low emission diesel engine (Euro IV) is more toxic against human macrophage cells than that one from an older diesel engine, highlighting how low-emission engine soot poses higher health risk per unit mass than the soot produced from an old engine operating under black smoke conditions [17-18].

In the present study we aim to compare the oxidative and inflammatory response, in vitro, of human dermal keratinocytes (NHKs) and fibroblasts (NHDFs) exposed to carbonaceous nanoparticles collected from a low emission Euro IV test heavy-duty diesel engine exhaust, with the response of the same cells to the carbonaceous nanoparticles from an older diesel engine.

\section{Experimental}

\subsection{Particle collection and characterisation}

The soot from a Euro IV test heavy-duty diesel engine will be referred to as Euro IV soot; the soot from an old diesel engine operating at black smoke conditions will be referred to as BS soot. The methods of soot production and collection have been described elsewhere [18]. Briefly, the Euro IV soot originated from a modified MAN D0836 LF- 4V six cylinder truck engine $(6.9 \mathrm{~L}$ displacement, 228 $\mathrm{kW}$ ), with two-stage controlled turbocharging, an externally controlled cooled exhaust gas recirculation, and a common rail injection system. The engine was developed to fulfill the Euro IV emission standard. The engine was set for a $\mathrm{NO}_{2}$ emission of $3.3 \mathrm{~g} / \mathrm{kWh}$ and a PM emission of 50 $\mathrm{mg} / \mathrm{kWh}$ (European stationary cycle, ESC). The BS soot originated from a D2876 CR truck engine, operated at 30\% load, extra-low rail pressure, and air throttling (blackening number 5). The emission rate of the BS engine was 200$600 \mathrm{mg} / \mathrm{kWh}$. The diesel fuel used for both engines was a standard low-sulfur type, containing $78 \%$ paraffin and $22 \%$ aromatic hydrocarbons (European Norm 590). All samples were collected directly from the exhaust gas of the engine using a special particle collector that was heated to the exhaust gas temperature at the collection position $\left(200^{\circ} \mathrm{C}\right)$. Transmission electron microscopy, energy-dispersive $\mathrm{X}$-ray spectroscopy, and temperature programmed oxidation studies revealed that Euro IV soot contained about $10 \%$ ash from the combusted engine lubricant oil. This kind of ash was not found in BS soot [17]. The mean size of Euro IV soot particles (small nuclei, $10 \mathrm{~nm}$; spherical particles, 18 $\mathrm{nm})$ was much smaller than that of BS soot $(35 \mathrm{~nm})$. The particulates were agglomerate of primary particles with sizes varying from 2 to $20 \mathrm{~nm}$ that showed multiple fullerene-like (F) shell structures. The agglomerates did not exhibit a defined profile or regular shape. BS soot revealed a totally different morphology from that of the Euro IV soot. It exhibited a secondary structure consisting of a number of agglomerated spherical particles much larger than the Euro IV particles. For the in vitro studies, the Euro IV and BS soot were sterilized by heating at $180^{\circ} \mathrm{C}$, at a temperature lower than that of the exhaust gas at the collection position $\left(200^{\circ} \mathrm{C}\right)$, in order to avoiding to affect the particle properties Then the particles were washed three times in distilled water, suspended in PBS at a stock concentration of $1 \mathrm{mg} / \mathrm{ml}$ and sonicated in a water bath at low intensity for $48 \mathrm{~h}$ before the use, in order to obtain a better dispersion of the particles that tend to agglomerate.

\subsection{Cell culture}

Primary cultures of normal human keratinocytes (NHKs) derived from neonatal foreskins as previously described, [19], were maintained in Medium 154 (Invitrogen, Life Sciences, Milan, Italy) supplemented with Human Keratinocyte Growth Supplement (HKGS, Invitrogen) plus antibiotics and $\mathrm{Ca}^{2+}(0.07 \mathrm{mM})$. Primary cultures of normal human dermal fibroblasts (NHDFs) were derived from neonatal foreskins. After digestion with dispase $0.1 \mathrm{mg} \mathrm{mL}^{-}$ ${ }^{1}$ (Gibco, Invitrogen) the dermis was incubated with collagenase $0.35 \%$ (Gibco, Invitrogen) for $45 \mathrm{~min}$ at $37^{\circ} \mathrm{C}$, centrifuged, resuspended and grown in D-MEM (Euroclone, 
Wetherby, West York, UK) supplemented with $10 \%$ heat inactivated fetal bovine serum (FBS) (Hyclone, Logan, UT, USA) and antibiotics and maintained in a humidified atmosphere of $95 \%$ air containing $5 \% \mathrm{CO}_{2}$ at $37^{\circ} \mathrm{C}$.

All treatments were performed in Medium 154 supplemented with $\mathrm{Ca}^{2+}$, penicillin-streptomycin but without HKGS and D-MEM without FBS to exclude any interference of these one with the treatments. For all experiments cells were seeded at passage numbers 3-5 and were treated upon reaching $80 \%$ confluence.

\subsection{Phase contrast and fluorescence microsco- py}

For microscopy analysis cells were plated on glass coverslips previously coated with $2 \%$ gelatin (Sigma Chemicals Co., St. Louis, MO) onto 24 well plates and exposed to the nanoparticles $(60 \mu \mathrm{g} / \mathrm{ml})$ for $24 \mathrm{~h}$ at $37^{\circ} \mathrm{C}$. Cells were then fixed with $4 \%$ paraformaldehyde in PBS (Euroclone) for $30 \mathrm{~min}$ at $25^{\circ} \mathrm{C}$. Nuclei were visualized using DAPI (Sigma Chemicals Co). Fluorescence signals were analyzed by recording stained images using a cooled CCD color digital camera (Zeiss, Oberkochen, Germany).

\subsection{Confocal laser Scanning Microscopy (CLSM)}

The analysis of particle uptake was carried out by CLSM on cells fixed with paraformaldehyde and counterstained with $1 \mu \mathrm{g} / \mathrm{ml}$ propidium iodide (PI). Confocal microscopic observation was carried out using the confocal microscope LEICA TCS SP5 (Leica Instruments, Heidelberg, Germany). The excitation/emission wavelengths employed were $568 \mathrm{~nm} / 590 \mathrm{~nm}$ for PI labelling respectively, while the soot particles were visualized by recording the deviation of the laser beam (black hue on or inside cells). The cell morphology was visualized by differential interference contrast (DIC), and merged images of the two signals (PI/DIC) were also recorded. In order to distinguish the signals stemming from particles internalized or from particles adhering on the surface of the cells, for PI staining, vertical sections, of $0.5 \mu \mathrm{m}$ in thickness, were acquired along the $z$ axis, from the top to the bottom of the cells.

\subsection{Cell viability}

NHKs and NHDFs were treated with soot particles at concentration of 30 and $60 \mu \mathrm{g} / \mathrm{ml}$. The viability of cultured cells was determinated at 24 and $48 \mathrm{~h}$ by assaying the reduction of MTT to formazan. After treatment, the cells were washed twice with PBS and MTT (final concentration $0.5 \mathrm{mg} / \mathrm{ml}$ ) was added. Cells were then incubated at $37^{\circ} \mathrm{C}$ for $2 \mathrm{~h}$, and Dimethyl Sulfoxide (DMSO) was added to dissolve the formazan crystal. Absorbance at $570 \mathrm{~nm}$ was measured by a spectrophotometer $\mu$ QUANT (BIO-TEK Instruments, Inc., Highland Park, Vermont, VT, USA). The results represent the mean of three experiments in triplicate. Cell viability was also determined by the trypan blue exclusion test method [20]. Cells were harvested by incubation in $0.5 \%$ trypsin and $0.2 \%$ EDTA for 10 minutes at $37^{\circ} \mathrm{C}$, and counted using a hemocytometer.

\subsection{Fluorescent measurement of intracellular oxidative stress}

Intracellular ROS were determined with 5-(and 6)carboxy-2', 7'-dichlorodihydrofluorescein diacetate, acetyl ester (CM- $\mathrm{H}_{2}$ DCFDA) (Molecular Probes, Eugene, OR, USA). Following exposure to soot particles for $1 \mathrm{~h}$, cells were washed twice with PBS and incubated with $5 \mu \mathrm{M}$ $\mathrm{CM}-\mathrm{H}_{2}$ DCFDA in 154 medium without phenol red at $37^{\circ} \mathrm{C}$ and $5 \% \quad \mathrm{CO}_{2}$. After $30 \mathrm{~min}$ incubation cells were trypsinized, centrifuged and resuspended in 154 medium without phenol red. Oxidative conversion of CM$\mathrm{H}_{2}$ DCFDA to the fluorescent product in living cells was assessed by flow cytometry using a FACSCalibur (Becton Dickinson, San José, CA, USA) equipped with a $488 \mathrm{~nm}$ argon laser. A total number of $1 \times 10^{4}$ cells were acquired from each sample. The CELL-QUEST software was used for analyzing the data. The median of the FL-1 channel of fluorescence was used as the measure of the intracellular content of ROS because it matches the maximal number of cells with the highest fluorescence.

\subsection{Plasma membrane integrity}

NHKs were plated on coverslips previously coated with $2 \%$ gelatin (Sigma Chemicals Co., St. Louis, MO) onto 24 well plates and exposed to the nanoparticles (30 and $60 \mu \mathrm{g} / \mathrm{ml}$ ) for 1 and $3 \mathrm{~h}$ at $37^{\circ} \mathrm{C}$. Cells were then washed in PBS and incubated for $1 \mathrm{~h}$ with Hoechst-33258 ( $5 \mu \mathrm{g} / \mathrm{l}$ in PBS). Samples were washed with PBS and fixed in $4 \%$ paraformaldehyde in PBS. The number of cells permeable to the Hoechst-33258 was determined by counting at lest 200 cells in randomly selected microscopic fields for each experimental point. Images were captured using a CCD camera (Zeiss).

\subsection{RNA extraction and Real time RT-PCR}

NHKs and NHDFs were stimulated with Euro IV and BS soot particles (30 and $60 \mu \mathrm{g} / \mathrm{ml}$ ) for 3-6 and $24 \mathrm{~h}$. After treatment, cells were washed with PBS and harvested for real time RT-PCR analysis. Total RNA was then isolated by the RNAse ${ }^{\circledR}$ kit (Qiagen, Hilden, Germany). Following DNAse I treatment, cDNA was synthesized using oligo-dT primers and RevertAid ${ }^{\circledR}$ M-MuLV reverse transcriptase 
(Fermentas Life Sciences, Hanover, MD, USA) according to the manufacturer's instructions. Quantitative real-time RT-PCR was performed in a total volume of $15 \mu \mathrm{l}$ with SYBR Green PCR Master Mix (Bio-Rad, Hercules, CA, USA), and a $200 \mathrm{nM}$ concentration of each primer. The primer sequences are for IL-1-alpha were sense: 5'CGCCAATGACTCAGAGGAAGA-3' and antisense: 5'AGGGCGTCATTCAGGATGAA-3' IL-6 were sense: 5'AGCCACTCACCTCTT-CAGAACG-3' and antisense: 5'GGTTCAG-GTTGTTTTCTGCCAG-3', for IL-8 sense: 5'CTTGGCAGCCTTCCTGATTTC-3' and antisense: 5'TTCTGTGTTGGCGC-AGTGTG-3' for TNF-alpha sense: 5'-CCAGGCAGTCAGATCATCTTCTC-3' and antisense: 5'-AGCTTGAGGGTTTGCTACAACAT-3', for MMP-3 were sense: 5'-GCTGCAAGGGGTGAGGACAC-3' and antisense: 5'-GATGCCAGGAAAGGTTCTGAAGTG-3', For MMP-9 were sense: 5'-GGGAGACGCCCATTTCG-3' and antisense: 5'-CGCGCCATCTGCGTTT-3' Nrf-2 and HO-1 and GAPDH primers were identical with those reported before [21]. Levels of gene expression in each sample were quantified applying the $2^{-\Delta \Delta C}$ method, using glyceraldehyde-3-phosphate dehydrogenase (GAPDH) as an endogenous control. Expression of each gene was assessed by at least three independent PCR analyses.

\subsection{Cytokine measurement}

NHK were treated with soot particles at concentration of 30 and $60 \mu \mathrm{g} / \mathrm{ml}$. After incubation for $24 \mathrm{~h}$ culture supernatants were collected and centrifuged for removal of cell debris. Aliquots were stored at $-80^{\circ} \mathrm{C}$ until use. IL- $1 \alpha$, TNF- $\alpha$ IL- 6 and IL- 8 protein levels were measured using a commercially available enzyme-linked immunosorbent assay SearchLight ${ }^{\circledR}$ human 4-Plex Array (Tema Ricerca, Bologna, Italy). The assay was performed according to the manufacturer's instructions. The results were normalized by protein levels in each sample and were expressed as $\mathrm{pg} / \mathrm{mg}$ total protein. Triplicate wells were used for each individual sample.

\subsection{Western-blot analysis}

The cell pellets were lysed in RIPA buffer containing a cocktail of protease inhibitors. The protein content was determined with Bradford reagent (Bio-Rad) using BSA as the protein standard. Equal amounts of protein (40 $\mu \mathrm{g} / \mathrm{lane})$ were resolved by $12 \%$ SDS-PAGE and transferred onto a nitrocellulose membrane. Protein transfer was checked with Ponceau S staining (Sigma). After non-specific binding sites were quenched using blocking buffer $5 \%$ non-fat dry milk in TBST (20 mM Tris-HCl, pH 7.4, $150 \mathrm{mM} \mathrm{NaCl}$, $0.05 \%$ Tween 20 ), the membrane was incubated overnight with primary antibodies specific for HO-1 (1:2000 dilution, Stressgen, Bioreagents, MI, USA) or tubulin (1:1,000 dilution, Santa Cruz, Biotechnology Inc., CA, USA). The blot was washed and incubated again with horseradish peroxidase-conjugated anti-rabbit and anti-mouse $\operatorname{IgG}$ secondary antibodies (Santa Cruz). After washing once again, protein levels were determined by chemioluminescence using an ECL detection system (Santa Cruz). The intensities of the bands were measured using the GS-800 Calibrated Image Densitometer (Bio-Rad).

\subsection{Statistical analysis}

All analyses were performed in at least three independent experiments. Data were reported as mean \pm SD. Statistical differences were evaluated using the MannWhitney test. P-values of 0.05 were regarded as significant.

\section{Results and discussion}

With this study we aimed to demonstrate that the biological behaviour of diesel nanoparticulate is strictly related to the microstructure of the particles, as we already observed in another cell type [17], and to evaluate the impact of environmental nanoparticulate on two skin cell systems that represent the first barrier against potential aggressive airborne pollutants, secrete pro-inflammatory molecules in response to foreign stimuli and interact with immune competent cells in activating immune-mediated responses [22]. We previously observed that fullerene-like nanoparticles from a low emission diesel engine (Euro IV) are more cytotoxic than particles from an older diesel engine and hypothesized [17] that the higher cytotoxicity could be related to the strongly defective structure of these particles, the high abundance of chemically reactive structural elements (edges), and the presence of surface functional groups that enable them to be phagocytised more readily by treated cells [23-25]. Keratinocytes in the skin are the first cells to be exposed to environmental stresses. There is increasing evidence that these cells play a significant role in the pathogenesis of various cutaneous and subcutaneous inflammatory diseases by releasing cytokines or by expressing membrane-associated adhesion molecules [10]. It is well known that these cells under normal physiological conditions, due to their protective role in the skin, do not possess the ability to internalise any foreign body materials. Anyway some reports show that nanosized particles, such as nickel oxide, aluminium and silver nanoparticles are internalised by these cells [26-28], but it has never been reported that carbonaceous nanoparticles can be spontaneously up taken by keratinocytes. Unexpectedly, we observed that normal keratinocytes in vitro are able to take up spontaneously diesel exhaust nanoparticles after $24 \mathrm{~h}$ exposure. Phase contrast and fluorescence microscopy analysis of exposed cells after DAPI staining of nuclei (blue) re 


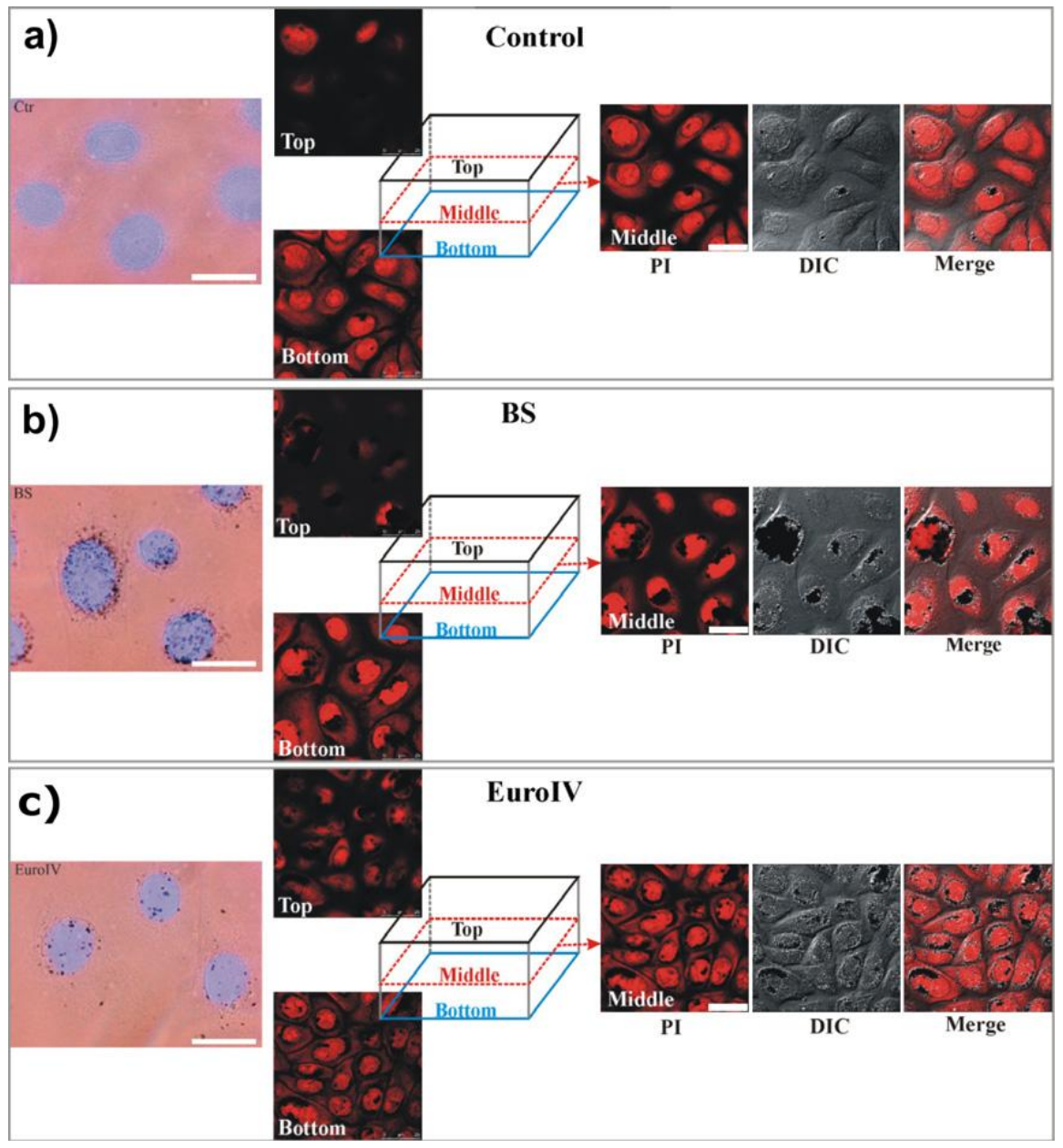

Fig. 1. Comparison of representative images of untreated and particles-exposed keratinocyte cultures. (a) Untreated control. (b), (c) Keratinocyte cultures after $24 \mathrm{~h}$ of exposure to $60 \mu \mathrm{m} / \mathrm{ml}$ BS or Euro IV particles, respectively. Left panels: microscopy analysis after DAPI staining of nuclei (blue) reveals the presence of internalised particles mainly localized in perinuclear area. BS particles show a more clustered distribution respect to Euro IV. Scale bars: $20 \mu \mathrm{m}$. Right panels: confocal microscopy representative images showing the uptake of soot particles by human keratinocytes. Cell morphology is visualized by differential interference contrast (DIC), the soot particles are visualised by recording the deviation of the laser beam (black hue on or inside cells). The cell cytoplasm and nucleus are visualised by fluorescent signal of propidium-iodide staining (PI, red hue). For each sample, the top, middle and bottom confocal sections, acquired along the $\mathrm{z}$ axis, are shown; merged images of the middle confocal section (PI staining) with the DIC signal are also reported. Scale bars: $25 \mu \mathrm{m}$.

vealed the presence of internalised particles mainly localized in the perinuclear area. BS particles showed a more clustered distribution respect to Euro IV particles (Fig. 1, left panels). Moreover, the analysis of particle uptake by confocal microscopy (Fig. 1, right panels) clearly showed that Euro IV particles were better dispersed and did not form big aggregates, as compared to the BS soot particles, which were observed to aggregate into big clusters. Both particles were internalised into the cell cytoplasm but Euro IV soot particles were observed in a higher amount into the intracytoplasmatic compartment as compared to the larger aggregates of BS and some Euro IV particles were also observed inside the cell nucleus.

Moreover, in order to assess cytotoxicity following exposure to these nanoparticles, NHKs and NHDFs were treated with different concentration of Euro IV and BS soot particles (30 and $60 \mu \mathrm{g} / \mathrm{ml}$ ) for 24 and $48 \mathrm{~h}$ and the MTT assay was performed (Fig 2 a, b). In parallel, the trypan blue exclusion test was performed to assess cell viability and membrane integrity under the same particle concentrations at $24 \mathrm{~h}$ (Fig $2 \mathrm{c}, \mathrm{d})$. These concentrations were selected as the lowest concentration able to affect the examined parameters, without inducing excessive cytotoxicity and in order to avoid the saturation of the response observed with higher doses, as previously reported [20]. MTT test showed (Fig. 2a, b) that the exposure of both cell types to nanoparticles induced a significant decrease in MTT metabolism, in a dose dependent manner, in comparison with unexposed cells ( $* \mathrm{P}<0.01$ vs control). Differences in MTT metabolism induced by the two types of nanoparticles were observed only in fibroblast cells, that were affected by Euro IV particles more significantly than 
a)

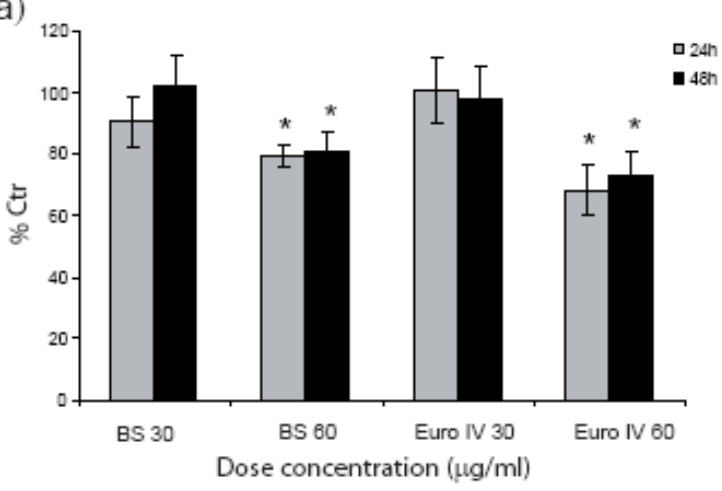

b)

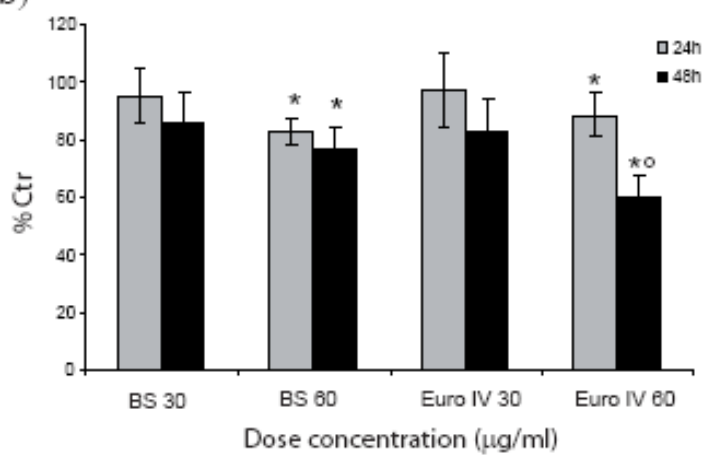

c)

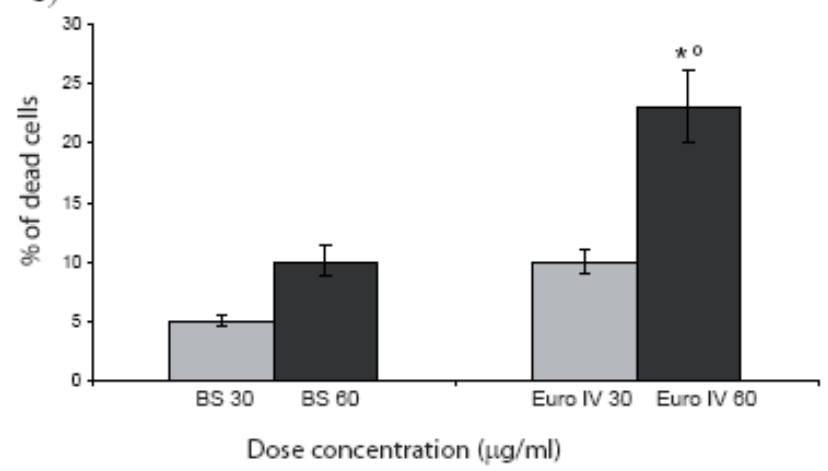

d)

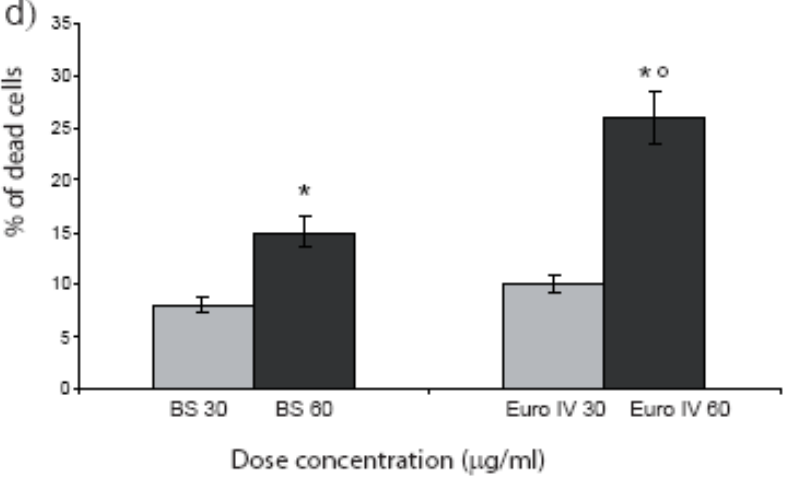

Fig. 2. Dose-response data testing the metabolic activity of BS and Euro IV particles on NHKs (a) and NDHFs (b), assessed after 24 and 48 h by MTT assay. Dose-response data testing the cytotoxicity of BS and Euro IV particles on NHKs (c) and NHDFs (d), assessed after 24 h by Trypan blue dye exclusion method. Each point represents mean \pm SD of values obtained from 3 replicate assay wells of three independent experiments $\left(* \mathrm{P}<0.01\right.$ vs control; ${ }^{\circ} \mathrm{P}<0.01$ Euro IV vs BS)

by BS particles $\left({ }^{\circ} \mathrm{P}<0.01\right.$ Euro IV vs BS). In addition, Trypan Blu test showed that the percentage of dead cells, as concerning both cell types, was higher after the exposure to Euro IV soot particles as compared to that one observed after the exposure to BS soot particles (Fig $2 \mathrm{c}, \mathrm{d}$; ${ }^{\circ} \mathrm{P}<0.01$ Euro IV vs BS). Since DEP has been demonstrated to induce oxidative stress, we analysed the intracellular generation of ROS following Euro IV and BS soot particle exposure in NHKs. Both types of soot particles induced a significant increase of ROS production in a dose dependent manner after $1 \mathrm{~h}$ treatment (Fig. 3 a). However the ROS levels were significantly higher in NHKs treated with Euro IV compared to NHKs treated with BS soot particles. Considering that ROS affect membrane stability we evaluated whether the oxidative stress induced by soot particles was also associated to the membrane damage. To this aim we assessed the membrane permeability using the DNA stain Hoechst-33258. Microscopy analysis, performed in NHKs exposed to BS and Euro IV nanoparticles at higher dose (60 $\mu \mathrm{g} / \mathrm{ml}$ ), revealed a significant membrane damage, as demonstrated by the increased number of cells permeable to the nuclear probe, as compared to untreated cells (Fig. 3 b, c). After $1 \mathrm{~h}$ treatment Euro IV particles, at both doses, were able to induce the membrane damage at a higher extent as compared to BS particles. $\left({ }^{\circ} \mathrm{P}<0.01\right.$ Euro IV vs BS) This difference was no longer significant after $3 \mathrm{~h}$ treatment. Despite the obtained results at 1 and $3 \mathrm{~h}$, where Euro IV particles $(60 \mu \mathrm{g} / \mathrm{ml})$ determined the permeabilization of plasma membrane of about $60 \%$ of treated cells, we did not observe, as revealed by both the cytotoxicity assays, a dramatic decrease of cell viability after $48 \mathrm{~h}$. Membrane damage induced by oxidative stress is not necessarily an event that leads to cell death. In fact, cellular plasma membrane integrity was partially rescued after $12 \mathrm{~h}$ nanoparticle treatment (data not shown).

Because the pro-oxidant capacity induced by whatever stimuli is almost always counterbalanced by the antioxidant processes put in place by cell defence systems, we evaluated the antioxidant capacity of NHKs challenged with the nanoparticulate, by analysing mRNA expression of Nrf-2, a key transcription factor, which regulates mRNA and protein expression of the antioxidant HO-1 molecule. HO-1 plays an important role as a stress protein with cytoprotective effects in addition to its role in heme catabolism [14]. Our results showed that both soot particles were able to induce Nrf-2 mRNA expression in NHKs at 3 and $6 \mathrm{~h}$ 


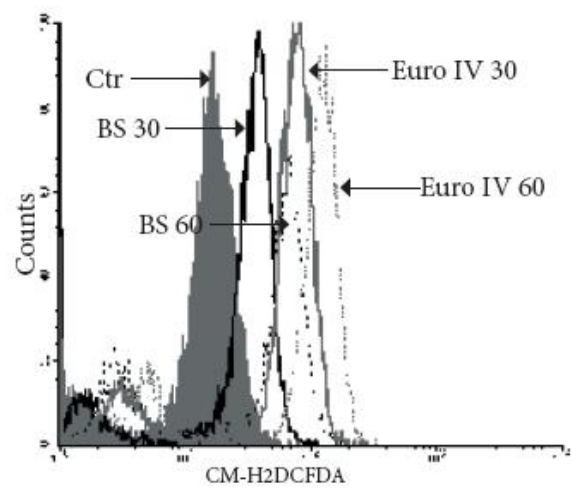

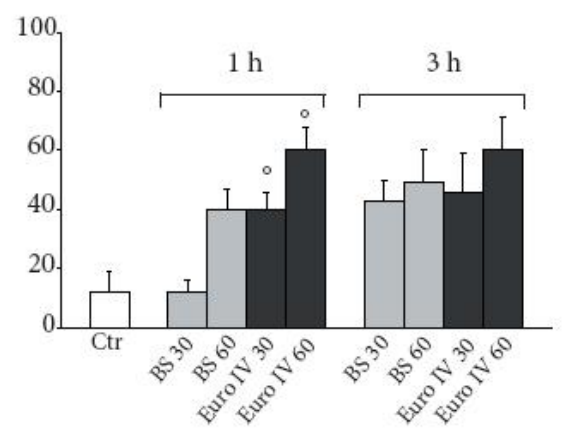

c
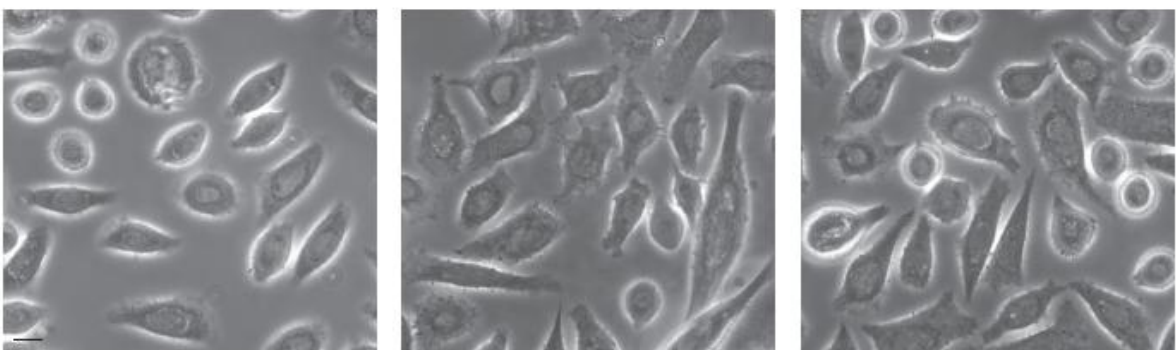

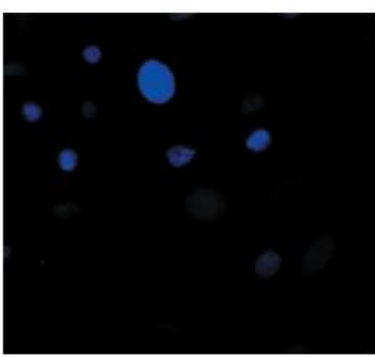

$\mathrm{Ctr}$

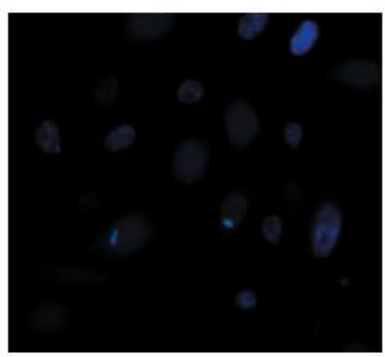

BS 30

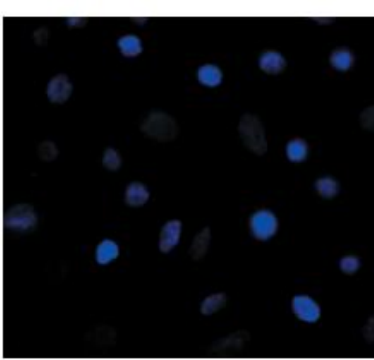

Euro IV 30

Fig. 3. Effect of BS and Euro IV particles on intracellular ROS accumulation in NHKs. Cells were stimulated with different doses of soot particles. After $1 \mathrm{~h}$, ROS production was determined by cytofluorimetric analysis using CM- ${ }_{2}$ DCFDA (5 $\mu$ M) as a fluorescent probe. (a) The histogram depicts a representative experiment of three independently performed experiments with identical results. Plasma membrane integrity analysis on untreated (Ctr) and particles-exposed NHKs (30 and $60 \mu \mathrm{g} / \mathrm{ml}$ ) for $1 \mathrm{~h}$ and $3 \mathrm{~h}$ using nuclear probe Hoechst-33258. The number of cells permeable to the DNA stain was determined by counting positive nuclei $(b, c)$. The data are the percentage mean value \pm SD of positive cells of two independent experiments performed in duplicate $(\mathrm{Bar}=20 \mu \mathrm{m})$.

$\left({ }^{\circ} \mathrm{P}<0.01\right.$ Euro IV vs BS)

but, while BS soot particles induced Nrf-2 mRNA expression in a dose dependent manner, the expression of Nrf-2 mRNA decreased when cells were exposed to the higher dose of Euro IV particles (Fig. 4 a; *P $<0.01$ vs control; ${ }^{~} \mathrm{P}$ $<0.001$ Euro IV vs BS). A similar trend was observed for the HO-1 mRNA expression at 6 h (Fig. 4 b; $* \mathrm{P}<0.01$ vs control; " $\mathrm{P}<0.001$ Euro IV vs BS). HO-1 protein expression, evaluated after $24 \mathrm{~h}$ particle treatment by Westernblot analysis, showed that HO-1 decreased when cells were challenged with both concentrations of Euro IV particles (Fig. 4 c, d; *P $<0.01$ vs control; ${ }^{\circ} \mathrm{P}<0.01$ Euro IV vs BS; ${ }^{\circ} \mathrm{P}<0.001$ BS vs Euro IV) ).

Our findings showed that fullerene-like soot particles produced under low-emission conditions exhibited, at the highest concentration $(60 \mu \mathrm{g} / \mathrm{ml})$, a higher cytotoxic and pro-oxidant effect towards keratinocytes, than particles from the older diesel engine. The highest cytotoxic effect could be responsible for the reduced mRNA expression of the antioxidant molecules Nrf- 2 mRNA and HO- 1 by the cells. Moreover, the incoherent results between HO-1 mRNA and protein expression induced by Euro IV treatment (30 and $60 \mu \mathrm{g} / \mathrm{ml}$ ) could be due to the fact that the study was not expanded for a longer time, therefore not giving us the opportunity to observe a higher protein expression coherent with mRNA results

It has been demonstrated that the oxidative stress is the central mechanism through which ambient PM induce adverse health effects [12]. The induction of Nrf-2- 
a)

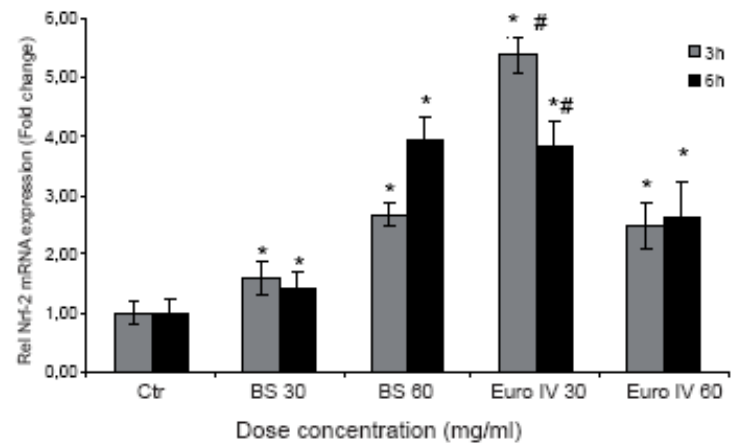

c)

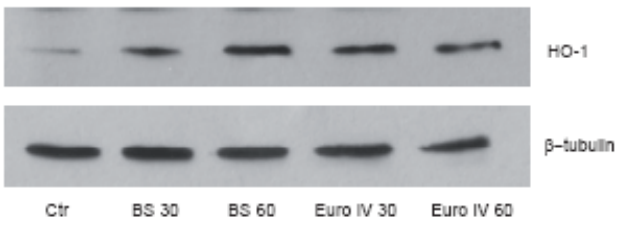

Dose concentration $(\mathrm{mg} / \mathrm{ml})$ b)

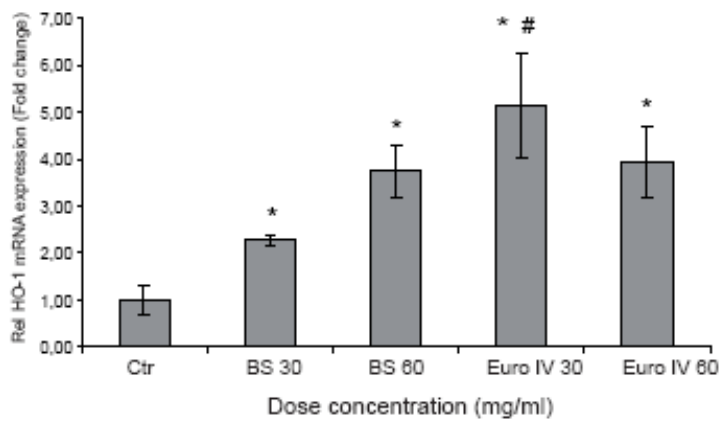

d)

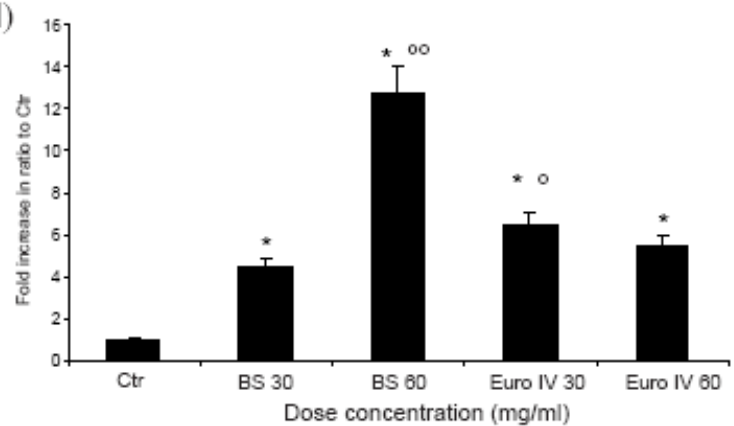

Fig. 4. Effect of BS and Euro IV particles on Nrf-2 and HO-1 expression in NHKs. Cells were stimulated with different doses of soot particles, as indicated, for 3-6-24 h. Relative mRNA level of Nrf-2 (a) and HO-1 (b) were determined by real time RT-PCR. Nrf-2 and HO-1 values are normalized against the expression of GAPDH and are expressed relative to untreated control cells. (c) A representative blot of HO-1 protein expression evaluated by Western-blot is reported. The protein loading was visualized by probing stripped blots for $\beta$-tubulin as shown. The band intensities were evaluated by densitometric analysis (d). Statistical significance between groups was assessed using the Mann-Whitney test. Results represent mean $\pm \mathrm{SD}$ from 3 independent experiments $\left(* \mathrm{P}<0.01\right.$ vs control; ${ }^{\circ} \mathrm{P}<0.01$ and ${ }^{\#} \mathrm{P}<0.001$ Euro IV vs BS; ${ }^{\circ} \mathrm{P}<0.001 \mathrm{BS}$ vs Euro IV).

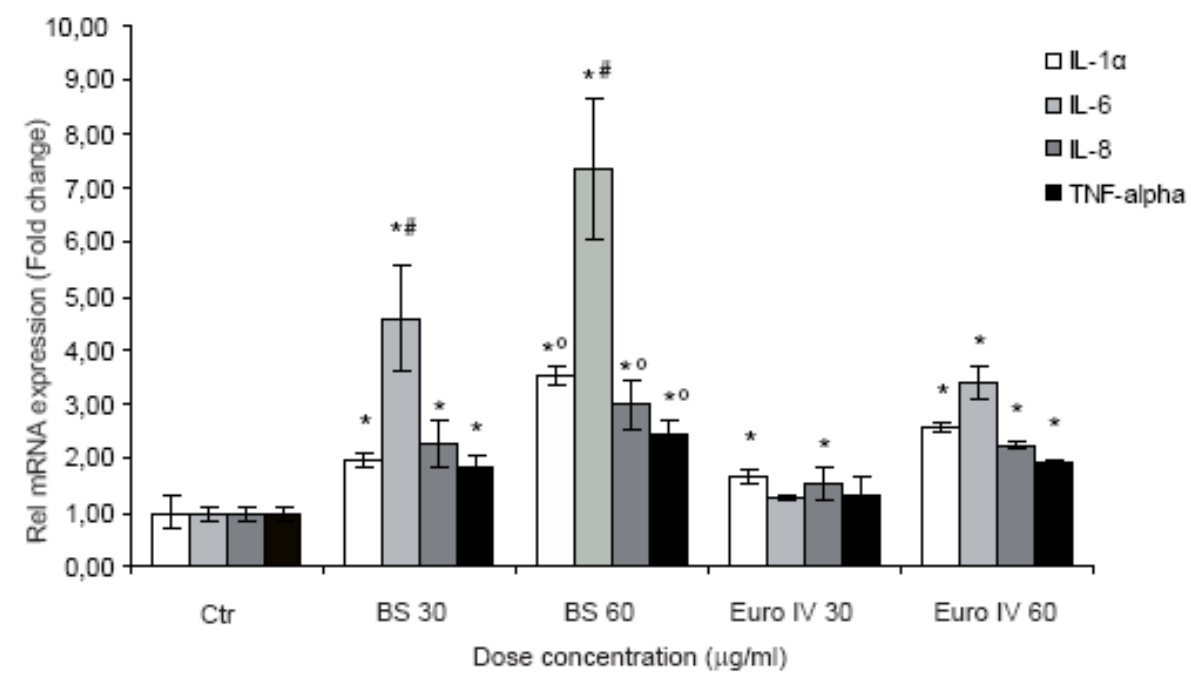

Fig. 5. Effect of BS and Euro IV particles on IL-1 $\alpha$, IL-6, IL-8 and TNF- $\alpha$ in NHKs. Cells were stimulated with different doses of soot particles, as indicated, for 6 h. Relative mRNA levels of pro-inflammatory cytokines were determined by real time RT-PCR. Statistical significance between groups was assessed using the Mann-Whitney test. Results represent mean \pm SD from 3 independent experiments $(* \mathrm{P}<<0.001 \mathrm{vs}$ control; ${ }^{\circ} \mathrm{P}<0.01$ and ${ }^{\#} \mathrm{P}<0.001 \mathrm{BS}$ vs Euro IV) 
a)

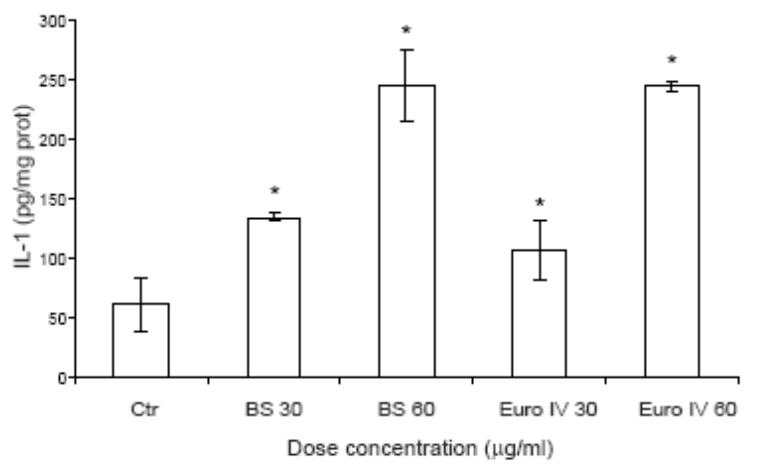

$\S$

c)

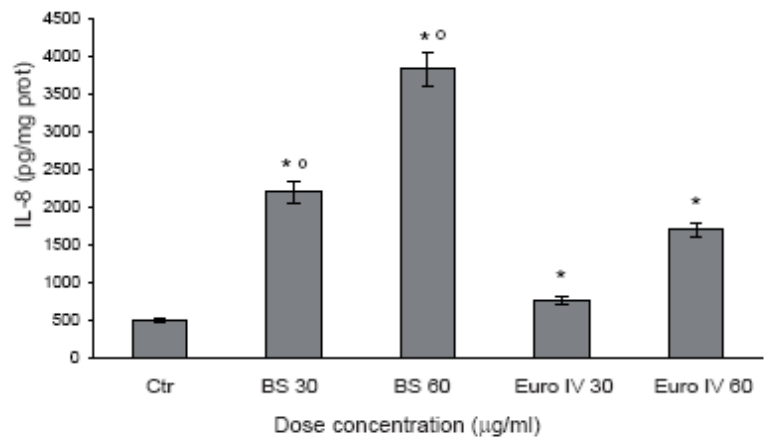

b)

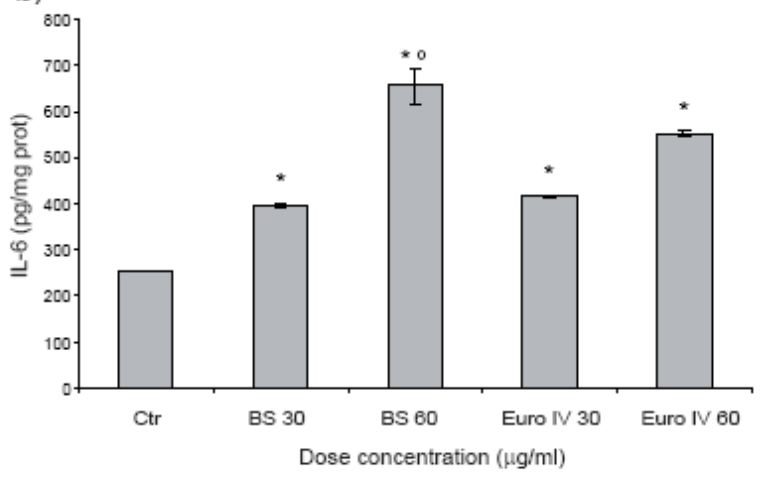

d)

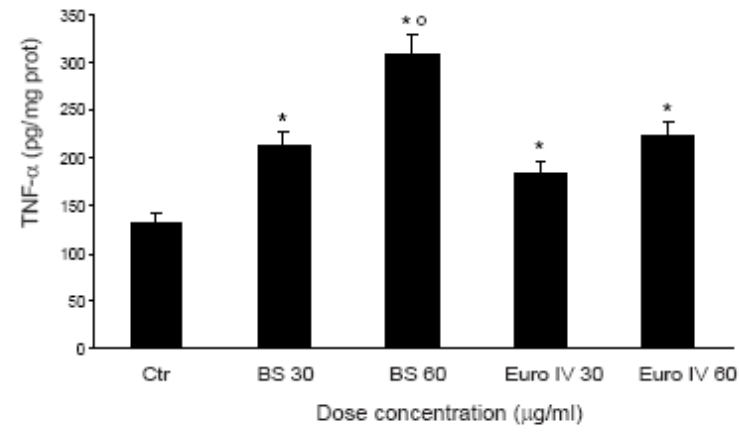

Fig. 6. IL-1 $\alpha$ (a), IL-6 (b), IL-8 (c) and TNF- $\alpha$ (d) levels in supernatants of NHKs stimulated with different doses of BS and Euro IV particles, as indicated, for $24 \mathrm{~h}$. Cytokines levels were measured by ELISA in duplicate for each individual point and are expressed in pg/mg protein. Statistical significance between groups was assessed using the Mann-Whitney test. Results represent mean \pm SD from 3 independent experiments $(* \mathrm{P}<$ 0.001 vs control; ${ }^{\circ} \mathrm{P}<0.001$ BS 30 vs Euro IV).

mediated phase II enzyme expression is an integral component of the cytoprotective response. This system is designed to prevent further oxidative stress, which may escalate into inflammation and cytotoxicity [13]. In fact, to neutralize the pro-oxidant effects of xenobiotics, higher animals have developed a finely coordinated battery of genes that encode phase II and antioxidant enzyme expression. This includes the expression of various enzymes that play a role in the response against the injurious effects of oxidative chemicals. HO-1, for instance, is a key antioxidant enzyme, regulated by Nrf-2 secretion, protecting against the cytotoxic effects of pro-oxidative DEP chemicals and ROS [14]. We observed that both types of soot particles induced a significant increase of ROS production in a dose dependent manner after $1 \mathrm{~h}$ treatment but keratinocytes exposed to Euro IV soot particles produced higher levels of intracellular ROS not counterbalanced by an effective cell antioxidant defence response, as shown by the reduced Nrf-2 mRNA and HO-1 mRNA expression from the cells exposed to the higher particle concentration. Cell failure to generate protecting mechanisms against the oxi- dative stress induced by Euro IV soot can explain the more pronounced cytotoxic effects exerted by these particles. In addition, we investigated the pro-inflammatory potential of the same particles evaluating their effect on the induction of IL- $1 \alpha$, IL- 6 , IL- 8 and TNF- $\alpha$ mRNA expression by keratinocytes, by Real time RT-PCR. The treatment of NHKs with BS soot particles strongly increased the mRNA levels of all pro-inflammatory cytokines measured, in a dose dependent manner (Fig. 5; *P $<<0.001$ vs control; ${ }^{\circ} \mathrm{P}$ $<0.01$ and ${ }^{\#} \mathrm{P}<0.001$ BS vs Euro IV). The treatment of NHKs with Euro IV soot particles induced a lower upmodulation of cytokine mRNAs, even at the highest concentration $(60 \mu \mathrm{g} / \mathrm{ml})$ and any significant changes for IL-6 and TNF- $\alpha$ at $30 \mu \mathrm{g} / \mathrm{ml}$ concentration (Fig. 5). To assess the relevance of the mRNA expression analysis, supernatants of cells exposed for $24 \mathrm{~h}$ to BS and Euro IV nanoparticles were assayed for their content of all pro-inflammatory cytokines. As expected, stimulation with both soot particles resulted in a marked increase in the secreted amounts of IL$1 \alpha$, IL-6, IL- 8 and TNF- $\alpha$. According to mRNA results the cytokine levels were higher in the supernatants of the cells 
exposed to BS soot than to Euro IV soot treatment (Fig. 6; $* \mathrm{P}<0.001$ vs control; ${ }^{\circ} \mathrm{P}<0.001$ BS 30 vs Euro IV). The stronger cytotoxic potential of Euro IV particles was confirmed by the observation that, even though the stimulation with both soot particles resulted in a marked increase in the secreted amounts of IL- $1 \alpha$, IL- 6 , IL- 8 and TNF- $\alpha$, the cytokine levels were higher in the supernatants of the cells exposed to BS soot than after Euro IV soot treatment. It can be argued that the lower cytokine levels observed in cells treated with Euro IV soot could be due to the higher cytotoxic potential of Euro IV nanoparticulate, as compared to BS. Furthermore, based on the recently demonstrated dermal absorption of nanoparticles [25] and aiming to explorate the potential involvement of other cell types in the pathogenetic mechanisms responsible for skin diseases induced by environmental factors, we also evaluated the effects of these carbonaceous nanoparticles on fibroblast activation by assessing the release of metalloproteases (MMPs) by dermal fibroblasts. It is well known that keratinocytes and fibroblasts interact with each other to maintain skin integrity, and dermal fibroblasts, activated by proinflammatory molecules produced by stimulated keratinocytes, secrete pro-fibrotic chemical mediators such as MMPs. We focused our attention on MMP-3 and MMP-9 which play a key inflammatory role in fibroblasts. Upon stimulation with both types of nanoparticles, the release of MMP-3 and MMP-9 was significantly increased in activated dermal fibroblasts. Fig. 7 shows the results of the NPs-induced MMP-3 and MMP-9 mRNA expression, after $24 \mathrm{~h}$, in dose-dependent manner $\left(* * \mathrm{P}<0.001\right.$ vs control; ${ }^{\circ} \mathrm{P}$ $<0.01$ Euro IV vs BS). It is noteworthy that the increase of MMP-3 levels was very high in cells treated with Euro IV particles. MMP-3 is more potent than MMP-9 as an activator of TNF- $\alpha$ release, thereby enhancing the pro-fibrotic course and influencing endothelial cell activation and recruitment of infiltrating leucocytes that are regarded as triggering factors for the induction of fibrosis.

Fibroblast-keratinocyte interactions are involved in the formation of the basement membrane zone, which is essential for attachment of the epidermis to dermis. It has been shown that keratinocytes, when co-cultured with fibroblasts, establish paracrine cytokine loops between the two cell types, in particular IL-1 $\alpha$, which levels were increased in the supernatants of treated keratinocytes, has been shown to exert various stimulating pro-inflammatory effects on fibroblasts [22]. Dermal fibroblasts are capable of responding to this pro-inflammatory stimulus through the up-regulation of MMP-3 and MMP-9 production. These MMPs are active against some extracellular matrix components and are thought to be responsible for the accompanying damage to connective tissue elements leading to fibrosis [19].

We suggest that the more dramatic in vitro effect of Euro IV particles, as compared to nanoparticles from the older diesel engine, on cellular responses could be due to the pronounced dissimilarity in microstructure and reactivity of these two kinds of carbonaceous nanoparticulate.

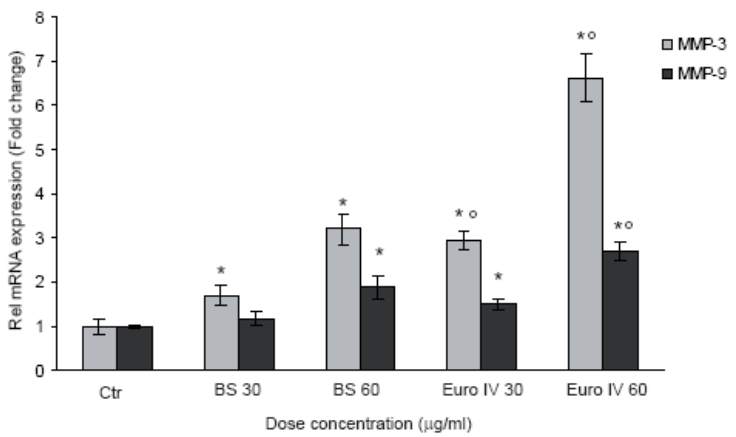

Fig. 7. Effect of BS and Euro IV particles on MMP-3 and MMP-9 in NHFs. Cells were stimulated with different doses of soot particles, as indicated, for $24 \mathrm{~h}$. Relative mRNA levels of MMP-3 and MMP-9 were determined by real time RT-PCR. $M M P-3$ and $M M P-9$ values are normalized against the expression of $G A P D H$ and are expressed relative to untreated control cells. Statistical significance between groups was assessed using the MannWhitney test. Results represent mean \pm SD from 3 independent experiments (**P $<0.001$ vs control; ${ }^{\circ} \mathrm{P}<0.01$ Euro IV vs BS).

These aspects have previously been studied in detail by high-resolution TEM (HRTEM) and electron energy loss spectrometry showing that Euro IV diesel nanoparticles have defective bulk and surface structure than BS soot particles, rendering it highly reactive [17]. One reason is the small size-distribution of primary particles and therefore the expected high surface area. However, the crucial reason seems to be the multi-shell like fullerenoid structure of the F-soot with defective surface that may produce highly localised olefinic electronic structures prone to the addition of molecular oxidants. One additional reason for the high reactivity of Euro IV soot is its defective surface being functionalised with volatile groups. The functionalized defective surface structure of the low-emission diesel engine soot, making Euro IV particles more reactives, could render them highly active also in a biological environment. Anyway, other nanoparticle properties could be important in their toxicity along with their dimension and surface structure. Thus, a further characterization of these nanoparticles is needed in order to definitively state that they pose a higher risk to the biosphere than the more conventional forms of large particle soot

\section{Conclusions}

In conclusion these data, showing that at the same mass concentration fullerene-like soot particles produced under low-emission conditions (Euro IV) exhibit an higher cytotoxic and oxidative potential, in vitro, than particles from the older diesel engine, are in agreement and confirm our previously published data obtained on human macrophages. Our findings suggest that environmental pollution by diesel exhaust carbonaceous nanoparticles from low emission diesel engines could be responsible for severe 
skin tissue damage. However, the results obtained in vitro could not exactly reflect the in vivo conditions due to either the difference of 4 to 12 folds in terms of emission levels of the particles or to the unknown concentrations of in vivo exposition We hypothesize that chronic exposure to them could lead to the development of skin pathologies characterized by the involvement of both superficial and deep layers of the dermal tissue. Our findings imply that a reduction of the emission rate of soot nano-particulate does not automatically lead to a reduction of the toxic effects toward humans if, concurrently, the structure and functionality of the soot changes and therefore its biological, cytotoxic and inflammatory potential, increase. Moreover, the increased

\section{References}

[1] Nemmar A, Hoylaerts MF, Hoet PH, Vermylen J, Nemery B. Size effect of intratracheally instilled particles on pulmonary inflammation and vascular thrombosis. Toxicol Appl Pharmacol 2003;186:38-45.

[2] Nemmar A, Al Maskari S, Ali BH, Al Amri IS. Cardiovascular and lung inflammatory effects induced by systemically administered diesel exhaust particles in rats. Am J Physiol Lung Cell Mol Physiol 2007a;292:L664-70.

[3] Diaz-Sanchez D, Proietti L, Polosa R. Diesel fumes and the rising prevalence of atopy: an urban legend? Curr. Allergy Asthma Rep 2003;3:146-52.

[4] Donaldson K, Tran L, Jimenez LA, Duffin R, Newby DE, Mills $\mathrm{N}$, et al. Combustion-derived nanoparticles: a review of their toxicology following inhalation exposure. Part. Fibre Toxicol. 2005;21:2-10

[5] Nel A. Atmosphere Air pollution-related illness: effects of particles. Science 2005;308:804-6.

[6] Ma JY, Ma JK. The dual effect of the particulate and organic components of diesel exhaust particles on the alteration of pulmonary immune/inflammatory responses and metabolic enzymes. J Environ. Sci. Health Part C Environ. Carcinog. Ecotoxicol. Rev 2002;20:117-47.

[7] Yamamoto S, Shwe TTW, Ahmed S, Kobayashi TK, Fujimaki $\mathrm{H}$. Effect of ultrafine carbon black particles on lipoteichoic acid-induced early pulmonary inflammation in BALB/c mice. Toxicol Appl Pharmacol 2006;213:256-66.

[8] Jaspers I, Sheridan PA, Zhang W, Brighton LE, Kelly D, Chason, KD, et al. Exacerbation of allergic inflammation in mice exposed to diesel exhaust particles prior to viral infection. Part Fibre Toxicol. 2009;14:6:22.

[9] Van Berlo D, Albrecht C, Knaapen Ad M, Cassee FR, GerlofsNijland ME, Kooter IM, et al. Comparative evaluation of the effects of short-term inhalation exposure to diesel engine exhaust on rat lung and brain. Arch Toxicol 2010;84:553-62

[10] Ushio H, Nohara K, Fujimaki H. Effect of environmental pollutants on the production of pro-inflammatory cytokines by normal human dermal keratinocytes. Toxicology Letter 1999;105:17-24.

[11] Smijs TG, Bouwstra JA. Focus on skin as a possible port of entry for solid nanoparticles and the toxicological impact. J Biomed Nanotechnol 2010;6:469-84.

[12] Aam BB, Fonnum F. ROS scavenging effects of organic extract of diesel exhaust particles on human neutrophil granulocytes and rat alveolar macrophages. Toxicology 2007;230:207-18 risk induced by the contact of these particles with different cell systems implies that further studies have imperatively to be addressed aimed to modify diesel engine characteristics and provide suitable filtering techniques to reduce health damage for humans and animals.

\section{Acknowledgements}

This study has been founded by GILS (Gruppo Italiano per la Lotta alla Sclerodermia).

[13] Li N, Alam J, Venkatesan MI, Eiguren-Fernandez A, Schmitz D, Di Stefano E, et al. Nrf2 is a Key Transcription Factor That Regulates Antioxidant Defense in Macrophages and Epithelial Cells: Protecting against the Proinflammatory and Oxidizing Effects of Diesel Exhaust Chemicals. J Immunol 2004;173:3467-81.

[14] Li N, Venkatesan MI, Miguel A, Kaplan R, Gujuluva C, Alam, J, et al. Induction of Heme Oxygenase-1 Expression in Macrophages by Diesel Exhaust Particle Chemicals and Quinones via the Antioxidant-Responsive Element. J Immunol 2000;165:3393-401.

[15] Warner RL, Bhagavathula N, Nerusu KC, Lateef H, Younkin $\mathrm{E}$, Johnson KJ, et al. Matrix metalloproteinases in acute inflammation: induction of MMP-3 and MMP-9 in fibroblasts and epithelial cells following exposure to pro-inflammatory mediators in vitro. Exp Mol Pathol 2004;76:189-95.

[16] Warner RL, Beltran L, Younkin E, Lewis CS, Weiss S, Varani $\mathrm{J}$, et al. Role of stromelysin 1 and gelatinase B in experimental lung injury. Am J Respir Cell Mol Biol 2001;24:1-8.

[17] Su DS, Serafino A, Müller JO, Jentoft RE, Schlögl R, Fiorito S. Cytotoxicity and Inflammatory Potential of Soot Particles of Low-Emission Diesel Engines. Environ Sci Technol 2008;42:1761-65

[18] Jacob E, D'Alfonso N, Döring A, Reisch S, Rothe D, Brück R, et al. PM-KAT: Nichtblockierende Lösung zur Minderung von Dieselruß für Euro IV Nutzfahrzeugmotoren. In 23. Intermationales Wiener Motorensymposium, 25.-26. April 2002, Band 2: Fortschritt-Berichte VDI Reihe 12 Nr. 490, Lenz, H. P. (Hrsg.); 2002; VDI-Verlag: Düsseldorf, 196-216.

[19] Pincelli C, Sevignani C, Manfredini R, Grande A, Fantini F, Bracci-Laudiero L, et al. Expression and function of nerve growth factor and nerve growth factor receptor on cultured keratinocytes. J Invest Dermatol 1994;103:13-8.

[20] Detrick-Hooks B, Borsos T, Rapp HJ. Quantitative Comparison of Techniques Used to Measure Complement-mediated Cytotoxicity of Nucleated Cells J Immunol 1975;114:287-90.

[21] Kokot A, Metze D, Mouchet N, Galibert MD, Schiller M, Luger TA, et al. Alpha-melanocyte-stimulating hormone counteracts the suppressive effect of UVB on Nrf2 and Nrfdependent gene expression in human skin. Endocrinology 2009;150:3197-206.

[22] Marchese C, Visco V, Aimati L, Cardinali G, Kovacs D, Buttari B, et al. Nickel-induced keratinocyte proliferation and up-modulation of the keratinocyte growth factor receptor expression. Exp Dermatol 2003;12:497-505. 
[23] Müller JO, Su DS, Jentof RE, Wild U, Schlögl R. Diesel Exhaust Emission: Oxidative Behaviour and Microstructure of Black Smoke Soot Particulates. Envirom Sci Technol 2006;40:1231-36.

[24] Cheung KL, Polidori A, Ntziachristos L, Tzamkiozis T, Samaras Z, Cassee, FR, et al. Chemical Characteristics and Oxidative Potential of Particulate Matter Emissions from Gasoline Diesel and Biodiesel Cars. Environ. Sci. Technol 2009;43:6334-40.

[25] Jeong SH, Kim JH, Yi SM, Lee JP, Kim JH, Sohn KH, et al. Assessment of penetration of quantum dots through in vitro and in vivo human skin using the human skin equivalent model and the tape stripping method. Biochem Biophys Res Commun 2010;394:612-5.

[26] Horie M, Nishio K, Fujita K, Kato H, Nakamura A, Kinugasa $\mathrm{S}$, et al. Ultrafine $\mathrm{NiO}$ particles induce cytotoxicity in vitro by cellular uptake and subsequent $\mathrm{Ni}(\mathrm{II})$ release. Chem Res Toxicol 2009;22:1415-26.

[27] Monteiro-Riviere NA, Oldenburg SJ, Inman AO. Interactions of aluminium nanoparticles with human epidermal keratinocytes. J Appl Toxicol 2010;30:276-85.

[28] Samberg ME, Oldenburg SJ, Monteiro-Riviere NA. Evaluation of silver nanoparticles toxicity in skin in vivo and keratinocytes in vitro. Environ Health Perspect 2010;118:407-13. 